\title{
Escola e Desenvolvimento Local: encontros e desencontros
}

\author{
Naira Lisboa Franzoi* \\ Damiana de Matos Costa França** \\ Maria Clarice Rodrigues de Oliveira***
}

\section{Resumo}

Este artigo apresenta reflexões sobre dois estudos de caso com estudantes trabalhadores: um com trabalhadores em engenho de cana de açúcar, no Nordeste do país; outro, com fumicultores gaúchos. Ambos abordam a relação entre formação de trabalhadores, saberes do trabalho e desenvolvimento local. Os dados foram produzidos a partir de autofotografias, no primeiro estudo, e de autobiografias, no segundo. Dentre as referências teóricas, tomam-se as teses de Schwartz e de Charlot, sobre saberes; e as de Francisco de Oliveira e Milton Santos, sobre desenvolvimento local. Os achados permitem reiterar que a escola só consegue revestir-se de sentido ao levar em conta o patrimônio cultural desses sujeitos.

Palavras-chave: Aluno Trabalhador. Saberes. Desenvolvimento.

\footnotetext{
* Doutora pela Universidade Estadual de Campinas (UNICAMP). Professora da Faculdade de Educação e do Programa de Pós-Graduação em Educação da Universidade Federal do Rio Grande do Sul (UFRGS).

${ }^{* *}$ Doutora em Educação pela Universidade Federal do Rio Grande do Sul (UFRGS).

**** Mestre e Doutoranda em Educação na Universidade Federal do Rio Grande do Sul (UFRGS).
} 


\section{Introdução}

Este texto é um esforço, dentre muitos empreendidos no âmbito de nosso grupo de pesquisa, de buscar uma articulação entre pesquisas individuais, para que proporcionem, continuamente, uma reelaboração teórica em novos patamares. Além disso, a dificuldade de falar sobre o próprio trabalho seja pela complexidade do fenômeno, seja pela dificuldade que o sujeito tem de reconhecer sua relevância - reforçam a demanda por novas metodologias de investigação dos saberes do trabalho, sem o uso exclusivo da linguagem verbal. Destaca-se a importância de criar estratégias e instrumentos metodológicos para conhecer os saberes do trabalho e a experiência em geral, os quais possibilitem tomar o saber como objeto de reflexão coletiva (CUNHA, 2010). Nesse esforço, o nosso grupo de pesquisa $^{1}$ vem buscando contribuir, através do estudo de metodologias e de investigações que recorrem à fotografia (MARTINS 2010), vídeo (GODINHO, 2010), autobiografia, entre outros, como estratégia para conhecer os saberes experienciais dos alunos. (FRANZOI et al, 2012)

Apresentam-se, pois, dois estudos de caso realizados isoladamente e que, neste artigo, ganham organicidade: um, com trabalhadores de um engenho de cana de açúcar, em uma cidade do nordeste brasileiro; e, outro, com fumicultores gaúchos.

Ambos os estudos tratam da produção de saberes pelos trabalhadores em situação de trabalho e sua articulação com a escola - matéria-prima teórica de todas as pesquisas desenvolvidas por nosso grupo. Os dois estudos foram analisados em conjunto porque, dentro deste espectro mais amplo, abordam a problemática do desenvolvimento local. Ambos têm também em comum o universo dos trabalhadores rurais, em municípios pequenos, ainda que em dois extremos do Brasil: no Nordeste e no Sul. Esta análise em conjunto torna-se possível porque, embora as realidades econômico-sociais das duas regiões possam ser consideradas muito distintas, a situação de exploração a que estão submetidos os trabalhadores do campo, nas feições que o capitalismo assume no Brasil, é uma só.

Fica evidente o desequilíbrio entre um e outro estudo: enquanto o estudo com os trabalhadores do Sul abrange diferentes estratégias para acercar-se do objeto, o estudo com os trabalhadores nordestinos limitou-se às autofotografias e entrevistas com os sujeitos em torno destas. Isto ocorreu pelo acesso que se teve a um e a outro grupo estudado ${ }^{2}$. Ainda assim, acredita-se que é válida a análise conjunta dos dois estudos, pois, se por um lado não nos possibilita comparações e conclusões mais categóricas, por outro fornece pistas a outros pesquisadores quanto a potências e fragilidades das estratégias metodológicas utilizadas. 
Tem-se como suposto que o sujeito está "engajado" em um mundo que compartilha com outros, histórica e espacialmente situados (CHARLOT, 2000). Outro suposto é a tese defendida especialmente por Schwartz, dentre outros, sobre a atividade de trabalho, segundo a qual toda situação de trabalho implica experiência, reencontro com um patrimônio herdado (SCHWARTZ; ADRIANO; ABDERRAHMANE, 2008). A partir de tais supostos, entende-se que os saberes e experiências dos sujeitos estão vinculados ao espaço local em que vivem, o que impõe a necessidade de buscar aportes teóricos relativos ao desenvolvimento local.

Considera-se local como sinônimo de território, tal qual definido por Milton Santos (1997, p. 96): “[...] o chão e mais a população, isto é, uma identidade, o fato e o sentimento de pertencer àquilo que nos pertence. O território é a base do trabalho, da residência, das trocas materiais e espirituais da vida, sobre os quais ele influi". A compreensão sobre desenvolvimento local, que se ancora principalmente em Oliveira (2001), é de que este não é um espaço harmônico e fechado em si, mas, ao contrário, é constituído de embates e negociações, atravessado pelas mesmas contradições do global.

Por fim, dão suporte a nossas análises, os aportes da ergologia (SCHWARTZ; DURRIVE, 2007), que, endossando as teses de Canguilhem (1990), ajudam a entender o sujeito em atividade de trabalho.

\section{Breves Notas sobre Desenvolvimento Local}

Parte-se da noção de desenvolvimento local em sua dimensão política, construído em oposição à concepção hegemônica, associada ao capitalismo globalizado. Esta é a premissa de Oliveira (2001, p. 19):

A maior parte das definições e ensaios de desenvolvimento local a rigor parecem-se mais com adaptações dos dominados do que alternativa à dominação: a própria dificuldade de definir o que "é desenvolvimento local" já é um indicativo suficientemente forte, posto que, se tudo é desenvolvimento local, então, como ensinava uma velha lição de álgebra, nada é desenvolvimento local. Esse é um meiocaminho, sem dúvida, pois não se trata de um conflito abstrato, mas de um real enfrentamento.

Para o autor, é necessário inventar um processo novo que não possa ser anulado, em que o desenvolvimento local seja entendido como tendência contrária aos processos dominantes (OLIVEIRA, 2001). A noção de desenvolvimento humano trabalhada pela Organização das Nações Unidas (ONU), que diz respeito à satisfação de um conjunto de requisitos de bem-estar e qualidade de vida, é 
necessária, mas insuficiente. A estas devem ser acrescidas outras dimensões decisivas. A primeira “[...] segue a trilha do conceito do subdesenvolvimento, na sua especificidade histórica, isto é, o não desenvolvimento local é um subdesenvolvimento no sentido forte de que ele é peculiar à periferia do capitalismo" (OLIVEIRA, 2001, p. 11). Para o autor, isto tem consequências teóricas e práticas. A primeira delas é a de que "[...] o desenvolvimento local não será o elo numa cadeia de desenvolvimento total; a segunda é que ou é concebido como alternativa ou reproduzirá a forma estrutural" (OLIVEIRA, 2001, p. 11-12). Outra consequência é que a cidadania apresenta-se como dimensão central para a construção de uma nova concepção de desenvolvimento local, pois "[...] é através desta que os cidadãos lutam pelo bem-estar e pela qualidade de vida, e não o inverso" (OLIVEIRA, 2001, p. 11-12). Segundo o autor, a luta pela cidadania

[...] é a forma mais moderna, contemporânea, do conflito de classes. Por que é a luta pelos significados, pelo direito à fala e à política, que se faz apropriando-se do léxico dos direitos e levando-os, redefinindo-os, num novo patamar, de fato transformando o campo semântico ao tempo em que se apropria dele. Em cada um dos fronts em que se realizam os conflitos contemporâneos, percebe-se o que está em jogo: os chamados "direitos adquiridos". (OLIVEIRA, 2001, p. 21).

Cidadania, aqui, “[...] refere-se ao indivíduo autônomo, crítico e reflexivo, longe, portanto do indivíduo-massa; trata-se de uma aquisição por meio do conflito" (OLIVEIRA, 2001, p. 12). Tal compreensão remete ao principal desafio do desenvolvimento local, dentro de uma perspectiva crítica, que se encontra em assumir a complexidade, ao invés de ignorá-la:

[...] do ponto de vista neoliberal, a cidadania é sinônimo de não-conflito[sic], de harmonia, de paz social, [...]. Como consequência, está-se elaborando um discurso sobre o desenvolvimento local como paradigma alternativo à sociedade plagada de conflitos por todos os lados; desenvolvimento local é apresentado como um "emplastro" (do romance de Machado de Assis, Memórias Póstumas de Brás Cubas) capaz de curar as mazelas de uma sociedade pervertida, colocando-se no lugar bucólicas e harmônicas comunidades. (OLIVEIRA, 2001, p. 13).

Nessa perspectiva, a escola é elemento fundamental da construção de uma concepção alternativa de desenvolvimento local, ainda que não seja o único.

\section{O Trabalho no Engenho de Cana de Açúcar e a Ausência da Escola}

No primeiro estudo de caso, os participantes foram instados a narrar-se e a narrar seu trabalho a partir de autofotografias, cujo objetivo era responder à pergunta: "Você se vê como partícipe do 
desenvolvimento de seu município? Como?”. Participaram quatro homens e quatro mulheres com idades entre 18 e 27 anos, que trabalhavam em diferentes atividades da produção de um engenho de cana de açúcar e residem no município de Areia, no estado da Paraíba.

Para a produção dos dados, utilizou-se o método autofotográfico (KOSSOY, 1998), que consiste na narrativa do sujeito a partir de imagens que ele produz sobre si mesmo, face ao tema que está em foco. Portanto, os sujeitos não são meros "participantes da pesquisa", mas tornam-se “coautores" dela. Neste estudo, cada um dos participantes recebeu uma máquina fotográfica descartável, com o pedido para que tirassem quantas fotos quisessem, a fim de responder à pergunta: "Você participa do desenvolvimento do seu município? Como?". Depois disso, os participantes deveriam selecionar as fotos que quisessem e legendá-las. Posteriormente, foram feitas entrevistas semiestruturadas, tendo como suporte a exposição das autofotografias ${ }^{3}$.

O meio rural no município de Areia, no nordeste do Brasil, parece conservar uma tradição de submissão, do período escravagista brasileiro, de maneira que quem trabalha para o senhor de engenho tem restrições ao conversar sobre sua situação de trabalho e remuneração. Nesse contexto, as autofotografias se mostraram um instrumento especialmente acertado pelas revelações que propiciaram. Através delas e do diário de campo, emergiu grande parte das constatações do estudo. Entendemos que foram elas que ajudaram os participantes a falarem das agruras de seu trabalho.

Todos os participantes responderam positivamente à pergunta que deu origem às fotografias, afirmando sua participação no desenvolvimento do município e que esta se dava através de seu trabalho. Nesse momento, apareceram muitas alusões positivas ao trabalho. Por exemplo, o fato de a cidade ser histórica, fazendo os engenhos parte do roteiro turístico, confere valor ao trabalho e aos trabalhadores, que, por isso, sentem orgulho do que fazem: "O nosso trabalho não desenvolveu só nossos engenhos, mas também a nossa cidade. Este produto é muito vendido não só na nossa região. Também vêm muitos turistas para visitar nossa cidade, que é patrimônio histórico, e visitam nossos engenhos" (Autofotografia, Ivanilda, 27 anos).

Além disso, o fato de o trabalho possibilitar o sustento, a ajuda em casa, também é motivo de orgulho: "Esse é outro tipo de trabalho (bagaceira), que eu desenvolvo com muito orgulho, é com esse trabalho por enquanto que eu ajudo meus pais e gosto muito de ajudar e ter minha determinada quantia para mim mesmo" (Autofotografia, Alexandre, 20 anos). 
O trabalho é também um lugar que oportuniza aprendizados e amizades:

[...] tudo aqui dentro do engenho convive com a pura ciência. (Autofotografia, Renato, 18 anos).

[...] eu decidi ajudar meu pai trabalhando nesse serviço que é muito cansativo, mas é muito importante, onde desenvolvi novas amizades e também aprendi a desenvolver novos serviços da agricultura. (Autofotografia, Alexandre, 20 anos).

Para Boris Kossoy (2000, p. 115), o resultado da fotografia depende do quanto o "[...] receptor projeta de si, em função de seu repertório cultural, da sua situação socioeconômica, de seus preconceitos, de sua ideologia, razão por que as imagens sempre permitirão uma leitura plural". O processo autofotográfico ampliou-se à medida que se levou em consideração o antes e o depois do ato fotográfico: os motivos, as escolhas, o momento do clique, o recorte da cena, entre outros aspectos. No ato de produzir as fotografias, os participantes foram conduzidos à reflexão sobre os elementos presentes em suas produções, sendo um meio utilizado por eles(as) para expor e evidenciar o que desejavam mostrar, o que queriam que fosse visto e a escolha sobre o que fotografar.

É importante destacar que a autofotografia é um amálgama entre as representações que o sujeito faz de si mesmo, como quer que os outros o vejam. Para além da mera representação, as imagens remetem aos estudos de Canguilhem (1990), endossados pela ergologia ${ }^{4}$ (SCHWARTZ; DURRIVE, 2007), sobre o trabalho como atividade humana, permitem entender a positividade encontrada no trabalho, apesar de condições tão adversas. Para a ergologia, a ênfase está em ver o trabalho do ponto de vista do trabalhador(a) e a relação que esse(a) estabelece com o meio no qual está engajado(a). Para Schwartz (2007, p. 26), é necessário fazer um esforço para “[...] ver de perto como cada um não apenas 'se submete' mas vive e tenta recriar sua situação de trabalho". Este autor, apoiado em Canguilhem (1990), compreende que o sujeito tem um impulso de vida que o leva à recriação da atividade, de maneira a preservar sua saúde.

No entanto, ainda que consigam encontrar positividades em seu trabalho, os participantes do estudo têm consciência de que este foi o que sobrou frente às suas oportunidades:

Aqui sou eu, nesse determinado trabalho. Essa foto mostra a dedicação para este trabalho. Esse trabalho é muito importante para mim e para os outros trabalhadores e agricultores daquela região, pois é um determinado trabalho que ninguém quer, mais a necessidade fala mais alto, principalmente para mim. Antes, eu nem sonhava em trabalhar nesse serviço, mais meu pai não estava conseguindo controlar todo o pagamento, as compras etc. (Autofotografia, Alexandre, 20 anos). 
O que emerge das fotografias com mais força são as dificuldades da vida no campo e as condições adversas de trabalho. Todos começaram a trabalhar na infância, em situação irregular, sem qualquer proteção para a realização do trabalho, num contexto de exploração, em que não existem direitos trabalhistas reconhecidos: “[...] veja, comecei a trabalhar aqui com quatorze anos, já fez dez anos que trabalho aqui, hoje estou com vinte e quatro anos, nada mudou, não têm os direitos, nada aqui é reconhecido. Só o motorista é que tem o documento assinado aqui” (Autofotografia, Fabiano, 24 anos).

Mesmo a aquisição dos itens de segurança no trabalho, como vestimentas adequadas durante a capinagem, são de iniciativa dos próprios trabalhadores. Eles são os únicos responsáveis pela própria proteção durante a realização das atividades no engenho.

São perceptíveis nas narrativas o desejo de mudar de vida e a luta estabelecida pelos jovens para alcançar seus desejos, entre eles o direito à educação. Por isso, o trabalho aparece como algo temporário. A necessidade da educação escolar é percebida a partir da realidade dos pais, que é associada à sua baixa escolaridade: "Meu pai é agricultor e analfabeto e isso mostra que eu tenho que fazer diferente, para que no futuro ele possa se orgulhar muito de mim” (Autofotografia, Alexandre, 20 anos).

Os projetos de futuro são muitos. Dentre eles, a graduação em Biologia, expressa por um dos participantes. Ou seja, a educação aparece como fator de ascensão social, de fuga do trabalho do engenho, um modo de construir um futuro diferente da situação vivida pelos pais. No entanto, os jovens e adultos do campo estão, em geral, abandonados à própria sorte, pois não contam com políticas públicas que contribuam para o rompimento da condição de exclusão em que se encontram. Portanto, não são socialmente reconhecidos como sujeitos de direito. Os jovens que fizeram parte deste estudo não são diferentes. Sem uma pesquisa mais aprofundada, seu nível de escolaridade em face de sua idade seria o suficiente para tal constatação. Os trabalhadores majoritariamente possuíam o Ensino Fundamental incompleto. Dos oito sujeitos da pesquisa, apenas dois estavam frequentando a escola regular. A maioria estava frequentando o Programa Projovem ${ }^{5}$, que se destina a atender jovens urbanos, sem vínculo formal de trabalho e com baixa escolarização.

No entanto, agrega-se a este dado a situação de invisibilidade a que estes trabalhadoresestudantes estão submetidos. Isso ficou flagrante no contato com as escolas que os jovens frequentavam: não existia qualquer conhecimento de sua situação de trabalho - aspecto central em suas vidas -, no que ele tem de sofrimento e no que tem de potência a ser mobilizada pela escola. 
Esse contexto certamente é responsável pela desesperança presente no depoimento dos jovens, lado a lado com os projetos e sonhos de estudar e, desse modo, ter uma vida melhor: "a escola é sempre uma luta, começo o ano e nunca consegui terminar" (Autofotografia, Fabiano, 24 anos).

\section{A Relação com o trabalho na fumicultura}

O segundo estudo de caso acompanhou dois jovens provenientes da zona rural do Rio Grande do Sul, alunos de uma escola técnica agrícola na região metropolitana de Porto Alegre. Para conhecer a realidade dos participantes, tomamos como fonte a sua autobiografia - texto escrito em uma das etapas do processo de "matrícula orientada" - como é definido o processo de ingresso da escola que frequentavam no momento da pesquisa, assim como o projeto de pesquisa e a pesquisa que desenvolveram durante o curso, entrevista na TV e rádio local, publicações em jornais e revistas sobre os desdobramentos da pesquisa e o desenvolvimento local.

Poderíamos supor que a situação dos jovens e adultos trabalhadores do campo no outro extremo do país, considerado rico, fosse muito diferente da encontrada no estudo anterior. Porém, o que se percebe é que a relação capitalista de exploração do trabalho borra fronteiras e peculiaridades. As relações com o trabalho na fumicultura também mostram uma realidade de exploração, de submissão do trabalhador a condições de trabalho que causam um sofrimento físico e emocional que pode ser comparado ao experimentado com a servidão, em pleno século XXI.

Jardel e Eder moram com suas famílias na zona rural de Venâncio Aires, um pequeno município do Rio Grande do Sul. Pelo menos há três gerações, trabalham na agricultura familiar no plantio do tabaco (fumo).

Como a maior parte dos agricultores que trabalham na fumicultura, a família de Jardel não tem a propriedade da terra onde seus pais e irmãos moram e trabalham - eles são meeiros ${ }^{6}$. Segundo ele, "[...] pior do que trabalhar de fumicultor é trabalhar de meeiro, é trabalhar com parcerias. [...] Quando chega ao final da safra, ele (o proprietário) reparte os lucros, não reparte o prejuízo, esse fica com o agricultor" (Jardel, entrevista). Os pais de Eder também trabalhavam como meeiros. Continuam a trabalhar na fumicultura, mas conseguiram comprar uma pequena propriedade.

Apesar de existir um contrato entre o agricultor e as empresas fumageiras (Sistema Integrado de Produção do Tabaco), os trabalhadores não têm seus direitos garantidos, pois esses contratos não garantem uma relação trabalhista com as empresas. Além disso, o trabalho está presente, desde muito 
cedo, no cotidiano da maioria das crianças e dos jovens do campo, principalmente nas atividades ligadas à fumicultura: “[...] tu acabas perdendo tua infância, tua adolescência [...] na época de safra, tu não tens dia nem final de semana. Na realidade, tu não percebes quando tu começas a trabalhar na lavoura" (Eder, Entrevista).

Jardel descreve como foi sua iniciação no trabalho na fumicultura: assumiu pequenas atividades na rotina doméstica, depois algumas responsabilidades na produção do fumo e, mais tarde, uma parte do trabalho entre os membros da família. Ele afirma ainda que, à medida que foi se tornando adulto, esse envolvimento com o trabalho na lavoura foi aumentando, o que contribuiu para que perdesse a vontade de estudar, antecipando na infância e na adolescência as responsabilidades de um adulto trabalhador. Seu relato, assim como o do outro participante do estudo, reafirma o que apontam as estatísticas: nas atividades agrícolas se encontram os maiores índices de trabalho infantil, especialmente na cultura do tabaco.

O trabalho na cultura do tabaco é um trabalho manual intenso, no qual o agricultor está exposto ao uso constante de agrotóxicos, a jornadas de trabalho sem descanso, ao endividamento, aumentando o vínculo de dependência com a indústria fumageira. Esses fatores associados levam os agricultores a problemas de saúde física e emocional, que começam na infância, passam pela adolescência e se estendem até a fase adulta. O endividamento é uma das causas dos problemas emocionais e psicológicos.

A realidade enfrentada com a cultura do fumo está fazendo com que os mais velhos fiquem sozinhos no interior. Como exemplo disso, Eder aponta a sua comunidade, na qual só permanece ele e a irmã, os demais jovens já saíram. Ele atribui sua permanência ao gosto pela agricultura e, por isso, buscou uma formação na área, enquanto os demais estão buscando outras formações e indo para cidade. Ele questiona o que será do interior em alguns anos.

Os entrevistados, bem como suas famílias, representam uma parcela da população brasileira que não teve garantido o seu direito à educação, à oportunidade de acesso ou permanência na escola. Entre os vários motivos que os afastaram da escola está a busca pela sobrevivência, realidade de muitas pessoas. Essa situação agrava-se nas regiões rurais e interioranas, associadas a questões de gênero, cor, raça/etnia, entre outras, ampliando as desigualdades econômicas, sociais e culturais dessas populações. Esses alunos-trabalhadores têm em comum as suas trajetórias escolares interrompidas, assim como as de suas famílias. 
Com relação à escolaridade de seus pais, Jardel e Eder revelam que por diversas razões não tiveram oportunidade de concluírem o Ensino Fundamental. Eder parou de estudar por três anos. Nesse período em que ele parou de estudar, trabalhou na agricultura; com os pais na fumicultura e, mais tarde, de empregado em uma fazenda. Mesmo com pouca escolaridade, os pais ensinaram-lhes as atividades de trabalho na agricultura e os valores que permeiam suas relações de vida e trabalho.

Também como os jovens do Nordeste, o desejo de mudar de vida os acompanha desde cedo. Quando completou 18 anos, Jardel pensou em sair do trabalho na fumicultura. Viu no serviço militar essa oportunidade, mas, para isso, foi necessário sair do campo e ir para a cidade. Em seu imaginário, na "cidade", ele teria melhores condições de trabalho e oportunidades de mudar de vida. A referência tomada aqui é a do espaço urbano idealizado como modelo de desenvolvimento e possibilidades de emprego, o que faz com que boa parte da população do interior, em sua maioria os mais jovens, acabem migrando para a cidade em busca dessas condições. Contudo, na maioria das vezes, o que esses jovens encontram não é sequer semelhante ao que imaginavam. Jardel faz referência a esse confronto de realidades: a do campo e a da cidade. Ele considera que não conseguiu se adaptar a uma cultura tão diferente da sua e voltou a trabalhar na fumicultura: "[...] saí de casa para servir o quartel, vi minha primeira chance de mudar de vida... buscar outra alternativa de trabalho. Vi meu sonho ir por água abaixo quando percebi que a cidade grande era tumultuada demais para mim” (Jardel, $1^{\text {a }}$ autobiografia).

Os alunos fazem uma reflexão sobre o quão difícil é enxergar todas essas questões que estão envolvidas nesse trabalho quando se está inserido nessa cadeia de produção:

[...] enquanto tu estás naquela cadeia, tu és vendado a ver muitas coisas. Muitas coisas são maquiadas (Jardel, entrevista).

[...] a gente, até por causa da rotina do trabalho, o que se está fazendo ali parece que não é tão complicado assim, mas quando tu te afastas e tu voltas pra ali tu enxerga com outros olhos [...] é muito difícil a realidade [...] (Eder, entrevista).

Ao falar sobre suas experiências de trabalho na fumicultura, esses dois alunos-trabalhadores fazem emergir toda a dramática história de vida e de trabalho de milhões de brasileiros trabalhadores, não só no meio rural, mas em todas as áreas em que o capitalismo subestima o ser humano, impondolhe o poder, a violência e a exploração. Por outro lado, suas experiências também permitem observar toda a potencialidade e a capacidade desses mesmos seres humanos de enfrentar essas situações, a partir do desvelamento dessa realidade, fazendo com que busquem incessantemente meios e formas para romper com esse ciclo em que se encontram.

Se até aqui as realidades dos jovens e adultos do Nordeste e do Sul se parecem, é com a 
oportunidade de frequentar uma escola que suas trajetórias se bifurcam. Retornar aos estudos e buscar uma formação profissional foi uma das alternativas que Jardel e Eder encontraram para enfrentar a realidade do trabalho na fumicultura, reafirmando assim que: "Os homens que criam [realidade] são os mesmos que podem prosseguir transformando-a" (FREIRE, 1988, p. 18).

\section{A Escola como fator de mudança}

Para que os alunos voltassem a estudar, foi necessário contar com o incentivo de algumas pessoas próximas. No caso dos dois, uma coincidência: foram pessoas com quem tiveram algum vínculo de trabalho que os incentivaram a retornar à escola e, principalmente, a fazer um curso técnico na área da agricultura.

Jardel encontrou esse apoio no "patrão" de seu pai, ou melhor, o dono das terras nas quais eles produzem como meeiros, um ex-aluno da ETA, que o aconselhava a voltar a estudar. Ele afirma que essa pessoa o fez acreditar na própria capacidade para superar aquela condição de afastamento da escola e buscar alternativas ao trabalho na fumicultura.

$\mathrm{O}$ ano passado eu conheci a ETA e simplesmente me apaixonei pela escola. Com a possibilidade também do crescimento social como pessoa e na carreira profissional, eu não pensei duas vezes em vir para escola em busca de conhecimento até mesmo para o mercado de trabalho (Jardel, 2008).

No momento do ingresso, Jardel queria ser um técnico da fumageira, ou seja, um instrutor, talvez atendendo à expectativa da família em relação a um possível emprego. Desde que nasceu, até aquele momento, ele estava imerso na realidade da fumicultura, o que o levou a assumir uma postura que Freire (2008) chama de "aderência" ao opressor.

Jardel estava vivendo a dualidade entre se libertar da opressão em que se encontrava como trabalhador na cultura do fumo ou continuar reproduzindo essa condição como orientador técnico dessa indústria. Mas ele buscava mais que isso, e a busca do conhecimento era um início dessa libertação: "Libertação a que não chegarão pelo acaso, mas pela práxis de sua busca; pelo conhecimento e reconhecimento da necessidade de lutar por ela" (FREIRE, 2008, p. 34).

Ao escolher continuar na agricultura, ele reconhece que a ideia que tinha no início do curso mudou totalmente. No entanto, o estudante reafirma a identidade e o gosto pela área da agricultura: 
[...] eu acho que eu não conseguiria fazer outra coisa diferente. Uma por experiência, eu já tinha uma experiência na agricultura e outra [por]que eu gosto desse ramo, da agricultura, [...] porque, se eu fosse fazer qualquer outro curso de profissionalização aí, uma informática, eu não estaria situado em uma coisa que eu ia me sentir bem [...]. É claro que a minha ideia de quando eu iniciei era uma e hoje é totalmente diferente, mas foi mais por experiência mesmo. (Jardel, entrevista).

A decisão de voltar a estudar, para Jardel, implicou em muitas preocupações e inseguranças, compreensíveis a partir das questões relacionadas à idade adulta, a uma maturidade adquirida e ao projeto de vida que estava ligado a essa decisão. Pensar em uma escola tão diferente da que havia estudado lhe dava esperanças, mas também causava temor. A preocupação central era sobre o seu desempenho escolar, a sua apropriação de saberes, os conhecimentos escolares, após esse longo período de afastamento.

É que a EETA, só por ser a EETA, ela já assusta, pela magnitude dela, pela, digamos assim, ela tem uma senhoria no ensino profissional. E, quando o aluno vem do interior, e, pior, aquele aluno que parou de estudar, como foi o meu caso, eu parei seis anos de estudar, eu tinha uma preocupação muito grande, porque eu pensava assim: "eu parei seis anos de estudar, primeiro, a minha idade é avançada e é fora do normal para uma pessoa que vai ingressar no ensino médio". Porque hoje o jovem está ingressando com 15, 16 anos e eu tinha 22 anos. Então, primeiro eu pensava na questão idade, se eu ia ser aceito pelos meus colegas. Depois eu pensava na questão de aula, eu ficava pensando [pausa]. Perdi noites pensando "será que eu vou acompanhar aquele aluno que saiu o ano passado da escola, eu que saí há seis anos? Será que vai ser a mesma coisa, será que eu vou conseguir ter o mesmo nível de aprendizado do que aquele aluno?" Então foi difícil, foi difícil [pausa]. Mas quando tu tens objetivo e, quando tu queres, tu não fazes desse problema o limite, pelo contrário, tu fazes desse problema uma conquista e essa conquista vai se tornar grandiosa. (Jardel, entrevista).

Transcrevemos este longo trecho da entrevista de Jardel porque é muito elucidativo do que talvez sejam os motivos que mantêm muitos jovens e adultos afastados da escola, por julgarem não ter condições de retornar a uma escola que está voltada para alunos de idade dita como "regular". Aí está uma questão para se pensar: como a escola que se propõe a receber os jovens e adultos pensa nesse acolhimento?

[...] eu me considero um pouco diferente. Não melhor, mas diferente dos meus irmãos, porque seria pouco continuar somente trabalhando ali. Eu pensava "tenho que seguir mais". [...] quando eu já estava mais maduro e a questão financeira também já me ajudava - porque o meu pai e a minha mãe não teriam condições de me ajudar - então, depois de seis anos eu voltei a estudar. Então isso para mim... [Jardel se emociona] Eu acho que só na decisão hoje de quem para, parou, sei lá, uma semana, um dia, um mês, anos [pausa]. Só de parar e pensar "eu vou voltar", essas pessoas já são vitoriosas. Não precisa nem concluir, só pensar de voltar já é grande coisa. E eu fiz bem mais. Eu não só pensei, eu voltei e me formei. Então é maravilhoso. (Jardel, entrevista). 
Contudo, Jardel fez uso de suas próprias capacidades, de seus recursos e escolhas para mobilizar-se e superar os próprios limites: "Fazer essas escolhas é também se engajar em um mundo humano atravessado de valores" (SCHWARTZ; DURRIVE, 2007, p. 194).

Eder, também sujeito desta pesquisa, considera-se um apaixonado pela agricultura. Como já foi relatado por ele, preferia o trabalho junto ao pai a estar na escola. Ele não se imagina fazendo outra atividade. Isso indica uma identidade com o meio, o gosto pela atividade e a construção de um patrimônio pessoal que se inscreve no tempo. Ele afirma, ainda, que as pessoas que trabalham nessa área são pessoas empenhadas e com muita vontade:

A agricultura, eu sempre digo: eu sou apaixonado por trabalhar nessa área, eu não me imagino trabalhando em outra área. Colegas, a gente vê também que as pessoas que trabalham nessa área são pessoas que trabalham empenhados. Porque eu acho que [é] a primeira coisa pra ti trabalhar com agricultura: nessa parte tu tem que ter vontade. (Eder, entrevista).

De forma semelhante ao que aconteceu com Jardel, foi incentivado pelo proprietário de uma fazenda, na qual sua família e ele trabalharam. Percebeu a diferença na condução das atividades, na fazenda, que eram orientadas por um técnico, e essa diferença estava no conhecimento: “[...] tinha um técnico na propriedade e a gente via que ele tinha uma diferença dos outros empegados. Ele era uma pessoa que tinha estudo, essa era a diferença dos que não tinham, sabe? Era visível. Então, aí começou, a minha curiosidade, a vontade de começar a estudar e fazer cursos" (Eder, entrevista, grifo nosso).

A reflexão que Eder fez sobre a diferença do conhecimento técnico e o trabalho na fazenda estava baseada no que ele observava e comparava com o trabalho na fumicultura, que ele conhecia muito bem, no qual não havia liberdade de inovar, de melhorar a técnica utilizada na lavoura e, principalmente, de manter cuidado no uso de agrotóxicos, um dos maiores problemas para a saúde do trabalhador e para o meio ambiente nessa cultura. Essas reflexões também levaram Eder a querer estudar e pensar na possibilidade de mudar essa realidade. O retorno à escola passou a ter um objetivo e um significado próprios para ele:

[...] eu acho que na fazenda de gado de corte, pelo Sr. Manoel, por eles [o técnico e a filha] terem um estudo, a gente via que eles aplicavam uma técnica, um conhecimento, sabe? [...] Eles inovavam e a gente via o resultado, entende? O resultado era visível. [...] uso de agrotóxico indiscriminado, lá não tinha isso, a gente usava o mínimo de agrotóxico possível, eles sabiam dos riscos, tinham conhecimento. (Eder, entrevista). 
Nesses relatos, existe uma relação de saber, na qual todos nós estamos imersos, pois ocupamos uma posição no mundo que é também uma posição do ponto de vista do saber, ou seja, relações entre grupos sociais que têm o saber como motivo, “[...] uma relação social fundada sobre as diferenças de saber" (CHARLOT, 2000, p. 85). Eder, o técnico, o pai e a filha, os dois engenheiros, “[...] eles não têm o mesmo saber, não dominam as mesmas atividades e as mesmas formas relacionais, existem diferenças sociais de legitimação entre esses saberes, atividades ou formas relacionais" (CHARLOT, 2000, p. 85). O mundo em que os seres humanos estão situados é estruturado por relações sociais, logo, toda relação com o saber é uma relação social de sentido e de valor. "A relação com o saber se constrói em relações sociais de saber" (CHARLOT, 2000, p. 86).

$\mathrm{Na}$ medida em que Eder reconhece o conhecimento e o fazer técnico desses profissionais, também se identifica com esse conhecimento. Com isso, busca na formação profissional a legitimação de tais conhecimentos e o reconhecimento através da profissão.

Ao conhecerem a ETA, esses alunos criaram uma possibilidade de construir uma nova perspectiva de relações com a escola, com a aprendizagem, com a formação profissional, e de crescimento pessoal "[...] uma escola é viva somente quando existe uma profunda e orgânica ligação entre ela e um específico dinamismo social objetivo que nela e com ela se identifica" (NOSELA, 1992, p. 57).

Para Charlot (2000), o essencial nessa perspectiva é a relação estabelecida com a escola, o "gostar", o se "apaixonar". Para esses alunos trabalhadores, o retorno aos estudos representava mais que um diploma: era um símbolo de crescimento pessoal e de cidadania.

O ano passado eu conheci a EETA e simplesmente me apaixonei pela escola. Com a possibilidade também do crescimento social como pessoa e na carreira profissional, eu não pensei duas vezes em vir para escola em busca de conhecimento até mesmo para o mercado de trabalho. (Jardel, Canal Rural).

[...] eu visitei algumas escolas do estado e não era bem aquilo que eu queria. Eu não me identificava muito bem com aquelas escolas. Até que eu fui conhecer a escola [ETA], eu gostei da instituição [...] Então eu fiz a inscrição, passei na seleção e iniciei no começo do ano, e, no momento em que tu estás juntando o útil com o agradável, tu faz tudo com vontade, tu te dedicas mais. E isso é muito interessante. (Eder, 2008, entrevista rádio).

Os dois jovens traduzem aqui as palavras de Charlot (2010, p. 152): “[...] um ensino é interessante quando um conteúdo intelectual encontra um desejo profundo". 
Estudamos muito, é bem puxado lá. Mas a gente tem que dividir, tem que saber dividir. Tu não podes se dedicar também só para uma coisa e deixar os estudos de lado. [...] A primeira impressão da escola é difícil, porque é tudo diferente. Tu tens que se adaptar a um novo ambiente. Mas após o momento em que tu começas a te adaptar, tu crias um vínculo muito forte com a escola, quase que lá é a tua segunda família. Qualquer problema, qualquer coisa, sempre tem alguém para te apoiar. É muito bonita a união da escola. (Eder, 2008, entrevista rádio).

Ao ingressarem na escola, os alunos desenvolvem uma pesquisa com o uso de fécula de batata doce como uma alternativa à fumicultura ${ }^{7}$. No projeto Uso da fécula da batata-doce como alternativa de renda para agricultura familiar, os alunos consideram a cultura existente dentro do sistema da agricultura familiar (PROJETO DE PESQUISA, 2009). Os alunos iniciaram a investigação a partir do que eles conheciam, ou seja, as culturas de subsistências produzidas pela agricultura familiar.

A possibilidade de o projeto contribuir para o desenvolvimento e a cultura local estão na concepção de um projeto endógeno, pensado e produzido a partir da pesquisa e da realidade local, tendo em vista uma inovação na produção de alimentos. A alternativa criada possibilita que os agricultores detenham os meios de produção para decidir o que produzir e como produzir de forma sustentável.

A partir dessa realidade e de suas experiências, os alunos encontraram uma forma artesanal de fazer a farinha e a fécula. Além disso, conseguiram ir mais longe: mudaram a forma de produção da bebida láctea "produzida e ensinada" pela escola e criaram alternativas não só para as suas realidades, mas para os demais colegas e para serem reaplicadas pela escola. Todo esse processo foi validado pelo aumento de produção e consumo pela comunidade escolar e pela comunidade em geral.

A pesquisa acabou por interessar à prefeitura de seu município, no sentido de implantar a cultura da batata doce - com vistas ao uso de sua fécula -, de forma a criar alternativas à cultura do tabaco, no âmbito da Convenção-Quadro ${ }^{8}$.

Foram muitas as transformações pelas quais Jardel afirma ter passado a partir da formação: “ter vontade de fazer" é diferente de "ter condições de fazer"; segundo ele, a formação escolar proporcionou tais condições. Ele ressalta a transformação humana que ocorreu, destacando as questões que envolvem a formação de valores, e como hoje ele vê o ser humano diferente. Suas palavras traduzem bem estes sentimentos:

A diferença é enorme, eu poderia ficar até dias falando do meu crescimento como pessoa e o do que a instituição me proporcionou; só que eu acho que nem assim mesmo eu iria conseguir traduzir em palavras o quanto eu cresci como pessoa, porque tu ter vontade de fazer as coisas é diferente do que ter condições de fazer. E a escola me deu condições. Eu tinha vontade e a escola me deu condições. Então eu 
não tenho nem palavras para dizer o tamanho que foi a minha transformação. $O$ que eu posso dizer é que hoje eu sou uma pessoa mais serena nas minhas decisões. A questão de aperfeiçoamento profissional, do estudo em si, te educa a ter decisões mais sóbrias [pausa]. Claro que a educação não vai evitar erros, todo mundo erra, mas tu erras menos. Hoje eu erro menos do que eu errava há um tempo. Hoje eu tenho mais paciência, eu tenho também mais vontade do que eu tinha há um tempo. Eu simplesmente não consigo olhar para trás e dizer que eu sou a mesma pessoa. $\mathrm{Eu}$ mudei muito. O Jardel de antes, aquele caráter continua, só que eu aperfeiçoei, entende? Mas as mudanças são nítidas para quem me conheceu há um tempo e para quem me conhece hoje. [...] $\mathbf{E}$ isso é fruto de vontade, é fruto de incentivo e fruto também de uma coisa que a gente deve levar muito em consideração, que é a família. Essa questão de família, não só aquela família de sangue, mas família de caminhada, porque na nossa caminhada hoje a gente encontra pessoas que nos puxam, pessoas pessimistas, pessoas que[pausa], mas até com essas a gente aprende. E, por outro lado, tem pessoas maravilhosas que nos incentivam. Então, isso também é um diferencial; antes talvez eu não desse tanto valor quanto eu dou valor hoje, dar valor para o ser humano, para as pessoas. Eu acho que eu poderia resumir isso em valores, os meus valores que eu tinha antes se modificaram, alguns continuam os mesmos, mas os meus valores, eles ganharam um acréscimo que eu, como ser humano, antes, não conseguia enxergar. $E$ hoje eu já tenho uma visão diferente. Então são simplesmente valores. (Jardel, entrevista, grifos nosso).

A professora Jane, orientadora da pesquisa desenvolvida pelos estudantes, também ressalta as transformações de Jardel:

Eu reconheço e vejo o quanto esses guris cresceram, quando eles chegaram à escola e como eles saíram. Homens com outras cabeças. Porque até o próprio Jardel, ele entrou para escola com um objetivo, ele tinha em mente um objetivo e mudou completamente. Ele veio para cá para deixar de ser um trabalhador do campo no ramo da fumicultura, para ser um orientador para esses agricultores. Então, o que aconteceu, essa troca foi muito importante, porque ele viu que existem outras possibilidades na vida, e foi daí que ele partiu, porque ele saiu do fumo e hoje ele está pesquisando a vitivinicultura. É uma mudança muito grande, e, quem sabe, ele consegue mostrar que é possível não só ficar em cima do fumo, mas também que realmente existem alternativas. Existem outras possibilidades para o agricultor se desprender um pouco desse convívio com essas empresas. (Jane, entrevista, grifos nosso).

Valeu a pena, valeu a pena. Nossa! Às vezes eu fico lembrando, quando eu comecei a estudar aqui, na primeira semana, duas vezes eu fiz a minha mala para voltar para casa. Aí eu pensei que o quanto eu ia me arrepender. Mas, daí eu pensei, de repente eu não ia me arrepender, porque eu não ia saber, eu nem imaginava, nem passava pela minha cabeça tudo que eu iria viver aqui e que vou poder viver a partir da vinda para escola. (Eder, entrevista).

Por sua vez, Eder afirma sentir, a partir do momento em que decidiu iniciar os estudos, uma diferença em sua vontade de aprender cada vez mais, com o aumento da sua curiosidade, e declara que 
as modificações não se restringiram ao âmbito das atividades de estudo e profissionais. O estudante afirma que se modificou enquanto pessoa:

A principal diferença é a vontade de aprender mais, é a curiosidade pelo conhecimento. Quando eu comecei aqui eu estava bem motivado, mas a gente, até por causa da tradição mesmo, eu gostava de estar na roça, de estar trabalhando, então começou as aulas: "Bah, mas isso". E hoje eu tenho vontade, eu me arrependo do tempo que eu parei de estudar, o qual foi fundamental pra voltar a estudar, mas eu me arrependo muito, e eu acho que é a vontade de estudar. Sem falar na pessoa, que isso é fora de série, a gente passa a ver a vida com outros olhos, chega a viver de outra forma. (Eder, entrevista).

Para Eder, a vontade de aprender cada vez mais aconteceu a partir da articulação de sua experiência pessoal de vida e trabalho, das relações de saber que o levaram a buscar na formação profissional um novo sentido e significado para a sua vida. Nessa articulação, ele encontrou motivos e razões para engajar-se nessas atividades de saber e trabalho.

No decorrer do tempo na Escola, nos atos de aprendizagem, convivência, problemas, conquistas, isso me despertou uma vontade de aprender cada vez mais, o que eu acho que será muito proveitoso para meu futuro. Meu foco era adquirir certo conhecimento para transmitir para minha comunidade. Mas com o decorrer do tempo parece que me caiu uma venda dos meus olhos, e agora vejo as coisas diferentes e pretendo ir mais além, conhecer novos lugares, levar e trazer diferentes conhecimentos técnicos. (Eder, $2^{\mathrm{a}}$ autobiografia).

A partir deste recorte das reflexões de Eder, em sua segunda biografia: "parece que me caiu uma venda dos meus olhos e agora vejo as coisas diferentes", podemos compreender que o processo de aprendizagem implica em mudanças, como afirma Charlot (2002, p. 32): “[...] aprender é mudar, formar-se é mudar. Não se pode aprender sem mudar pessoalmente porque se estou aprendendo coisas que têm um sentido, vou mudar minha visão do mundo, minha visão de vida".

A professora Jane também relata as mudanças que observou em Eder, desde o ingresso na escola até o momento em que estiveram envolvidos no projeto.

Uma coisa que deu para observar foi o crescimento deles como pessoas. Porque assim, se você olhar as entrevistas e as conversas feitas no início do projeto e olhar as do final, tu vais ver a desenvoltura deles. Não o Jardel, que já é uma pessoa que já tem facilidade de expressão. Mas o crescimento do Éder é assim fantástico. Então, o que aconteceu: a nossa preocupação com eles não foi só na formação profissional, eles foram lapidados como cidadãos, como seres humanos. (Jane, entrevista). 
$\mathrm{Na}$ entrevista, na rádio de Venâncio Aires, os alunos foram questionados pela apresentadora do programa sobre o que eles pensavam sobre a possibilidade de ter uma escola técnica federal na cidade. Eles responderam o seguinte:

Ainda mais por ser federal, né, porque tem uma ajuda maior do governo. Eu acho que é um projeto muito bom, ele só tem a acrescentar pelas oportunidades de trabalho que ele oferece ao jovem após se formar (Eder, 2008, entrevista-rádio).

Pela questão da concorrência do mercado de trabalho que, não basta tu ter um ensino médio ou um ensino fundamental, tu tens que procurar se qualificar. Esse tipo de curso como está vindo para Venâncio Aires esse colégio, esse CEFET, é importantíssimo que a comunidade faça uma movimentação para que os filhos das famílias possam ter acesso a esta escola. (Jardel, 2008, entrevista rádio, grifo nosso).

Eles destacaram a importância de uma instituição de educação profissional para a formação dos jovens, para que tenham oportunidades de formação e trabalho. Observamos que Jardel dá um destaque para que a comunidade faça um movimento para garantir o acesso a essa instituição, afinal, ter a escola na cidade não garante o acesso, principalmente de jovens e adultos do campo com baixa escolaridade. A partir de suas experiências, para Jardel, o acesso à educação ainda não é um direito universal. Na fala de Jardel, podemos ter ideia da luta necessária pelo direito à educação das populações menos favorecidas, por uma educação pública, gratuita e de qualidade.

No caso do trabalho na fumicultura, o acesso à escola também está vinculado a melhores condições de vida e trabalho, para que as crianças, jovens e adultos possam, além de "ter o direito", "se dar o direito" à educação para frequentar a escola. As experiências de Jardel e Eder no trabalho com a fumicultura, na escola e na formação profissional foram atravessadas pelos confrontos de realidades, valores e culturas, mas principalmente, como descrito por eles mesmos, de muito "querer", ou seja, de muita "vontade" para realizar seus projetos de vida. Nesse enfrentamento, esses jovens estão construindo as suas próprias histórias.

Todas as questões do cotidiano desses jovens os levaram a vencer e a ultrapassar fronteiras. Como Jardel afirma, "não se pode fazer dos problemas o limite e sim fazer dos problemas as conquistas". Na mesma direção, Eder avalia que vencer os obstáculos exige primeiramente ter "vontade" de aprender e de reescrever a história.

Quanto aos planos para o futuro, Eder diz que são de estudar, estudar. Para aquele jovem que preferia estar trabalhando a ir à escola, Eder descobriu o prazer de estudar. Para Jardel, os planos são continuar estudando e pesquisando na área da agricultura. 


\section{Palavras Finais}

Sem pretender estabelecer uma comparação direta entre os dois estudos de caso, dado o já referido aprofundamento desigual de ambos, a análise conjunta nos permite ver semelhanças e especificidades.

Em primeiro lugar, no que concerne à metodologia, quando se trata de dar visibilidade ao próprio trabalho, reforça-se a importância de lançar-se mão de diferentes estratégias. A autofotografia pode ser mais bem explorada. Em estudos recentes (FRANZOI, 2012) temos recorrido à confrontação cruzada - instrumento da clínica da atividade -, que consiste no diálogo entre os diferentes sujeitos produtores das fotografias acerca da produção fotográfica, o que expande as possibilidades de visibilização (CLOT, 2007).

Quanto aos resultados, uma das possíveis aproximações entre os estudos é o fato de que os jovens do primeiro estudo e os do segundo não são diferentes no que concerne às suas potências. Conhecem e elaboram saberes no seu trabalho, descobrindo nele a "ciência" que ele contém, recriandoo e extraindo dele, no limite das possibilidades, seu vigor, vitalidade e motivo de orgulho, para dar-lhe algum significado.

Propusemo-nos, com o primeiro estudo de caso, a contribuir com a discussão acerca da noção de desenvolvimento local, a partir do posicionamento e da reflexão dos/das trabalhadores(as)estudantes, enquanto protagonistas do seu próprio destino, conhecedores e construtores dos saberes sobre o lugar onde vivem.

Embora os limites do estudo não nos permitam conclusões em uma só direção, foi possível perceber a ausência da escola e, quando presente, um total desconhecimento da realidade dos estudantes por parte da mesma. A ausência da escola e de qualquer oportunidade de ir além de sua realidade, bem como a invisibilidade desses jovens, são evidentes.

Uma pergunta que permaneceu sem resposta foi se a escola teria potência para intervir em uma realidade tão adversa, tornando-se um espaço de reflexão sobre o desenvolvimento que se deseja para os(as) trabalhadores(as)-estudantes que se percebem como protagonistas do desenvolvimento.

No segundo estudo, há possíveis respostas a essa indagação. Aqui se percebe as possibilidades abertas pela educação escolar. Nessa perspectiva, não se constata simplesmente o papel da escola, mas afirma-se que ela só tem sentido e é capaz de fazer a diferença se os processos educativos forem pensados de forma articulada à realidade histórica e social em que os sujeitos estão inseridos, com suas 
tensões e contradições. Isso significa uma ruptura da mera transmissão de conhecimentos e abre espaço para que os estudantes-trabalhadores também produzam saberes, a partir de suas experiências, fazendo com que a escola assuma o seu sentido educativo. Nessa formação, o trabalhador deverá estar no centro do processo de ensino-aprendizagem, em que o trabalho é eixo articulador, para que a formação integrada se torne um espaço privilegiado para conferir ao trabalho um lugar de dignidade.

Os alunos e a professora destacam, para além da formação e da construção de saberes, a transformação pessoal e social pela qual todos passaram, inclusive a professora. Esse é o objetivo maior da educação, contribuir para que haja um crescimento pessoal para além da profissionalização. No entanto, apesar do conflito, da contradição e da condição de opressão vivida pelos alunostrabalhadores na fumicultura, os saberes e os valores do/no trabalho na agricultura contribuíram para a reflexão e o desvelamento dessa mesma realidade. O desenvolvimento da capacidade crítica e reflexiva desses alunos apontou para a importância de que a escola promova um espaço de valorização dessas experiências de vida e trabalho. Essas experiências dos alunos têm um grande potencial a ser descoberto e valorizado, não só pela escola e pelos professores, mas pelos próprios trabalhadores, para que essa (re)significação da experiência e do saber faça brotar e "florescer" novas alternativas de vida e trabalho.

\section{Nota}

${ }^{1}$ Projeto de pesquisa interinstitucional envolvendo Universidade Federal do Rio Grande do Sul (UFRGS), Universidade do Vale do Rio dos Sinos (Unisinos) e Universidade de Caxias do Sul (UCS).

${ }^{2}$ A pesquisadora trabalhava como coordenadora pedagógica da escola em que se desenvolveu o segundo estudo.

${ }^{3} \mathrm{O}$ método foi objeto de outros trabalhos das autoras.

${ }^{4}$ A ergologia é uma abordagem que compreende a atividade humana como um debate de normas (SCHWARTZ; DURRIVE, 2008).

${ }^{5}$ O programa Projovem nasceu no ano de 2007 de uma integração de seis programas já existentes: a) Agente Jovem, do Ministério do Desenvolvimento Social e Combate à Fome; b) ProJovem, da Casa Civil; c) Saberes da Terra e Escola de Fábrica, do Ministério da Educação; d) Consórcio Social da Juventude e Juventude Cidadã, do Ministério do Trabalho e Emprego. O programa encontra-se organizado em quatro grupos: ProJovem Adolescente; ProJovem Urbano; ProJovem Trabalhador, e ProJovem Campo - Saberes da Terra (BRASIL, 2008).

${ }^{6}$ Essa é uma forma de arrendamento em que o agricultor não tem a propriedade e "aluga" a terra para produzir. No caso dos pais de Jardel, o pagamento do aluguel é realizado entregando $50 \%$ da produção ao proprietário da terra. Essa forma de acesso à terra para produzir é muito comum entre os fumicultores.

${ }^{7}$ A pesquisa como princípio educativo faz parte da proposta pedagógica da escola. A pesquisa dos alunos foi apresentada em detalhes em textos anteriores (autora c, 2011; autora a e autora c 2013).

${ }^{8}$ A Convenção-Quadro para o Controle do Tabaco é um tratado internacional, que busca medidas para a redução do tabagismo. Na medida em que isso ocorrer, vai reduzir também a produção do tabaco, do qual o nosso país é o maior exportador do mundo. Essa redução vai refletir sobre os produtores e na economia das regiões que produzem essa cultura. Esse tratado, entre outras ações, prevê a diversificação da 
produção dos fumicultores como forma de diminuir o impacto na redução sobre renda familiar dos que vivem dessa cultura, bem como na economia local. São mudanças de caráter mundial que vão ter consequências locais.

\section{REFERÊNCIAS}

BRASIL. Decreto n ${ }^{\circ} 6.629$, de 4 de novembro de 2008. Regulamenta o Programa Nacional de Inclusão de Jovens - ProJovem. Diário Oficial da União, Brasília, DF, 5 nov. 2008.

CANGUILHEM, G. O normal e o patológico. Rio de Janeiro: Forense Universitária, 1990.

CLOT, Yves. Trabalho e sentido do trabalho. In: FALZON, Pierre (Ed.). Ergonomia. Tradução de Laerte Idal Sznelwar. São Paulo: Edgard Blücher, 2007.

CUNHA, Daisy Moreira. Problemas de Trabalho e Questões de Linguagem. Educação e Realidade, Porto Alegre, v. 35, n. 1, p. 49-69, jan./abr. 2010.

CHARLOT, Bernard. Da relação com o saber: elementos para uma teoria. Tradução de Bruno Magne. Porto Alegre: Artes Médicas, 2000.

CHAVES, Eder Renato; MENDONÇA, Jardel. Relatório Projeto de Pesquisa: Uso da Fécula de Batata Doce como Alternativa de Renda para Agricultura Familiar - EETA. Porto Alegre, 2009.

DUBOIS, Philippe. O Ato Fotográfico e outros ensaios. Campinas: Papirus, 1994.

FRANZOI, Naira Lisboa et al. Trabalhadores em sala de aula: o que a escola conhece sobre os saberes experienciais de alunos do PROEJA? In: FRANZOI, Naira Lisboa et al. Currículo e saberes do trabalho na educação profissional: estudos sobre o PROEJA Pelotas: UFPEL, 2012. (Coleção Pesquisa PROEJA no Rio Grande do Sul, v. 1). p. 177-198.

FREIRE, Paulo. Educação e Mudança. 14. ed. Tradução de Moacir Gadotti e Lilian Lopes Martin. Rio de Janeiro: Paz e Terra, 1988. (Coleção Educação e comunicação).

FREIRE, Paulo. Pedagogia do oprimido. 47. ed. Rio de Janeiro: Paz e Terra, 2008.

KOSSOY, Boris. Realidades e ficções na trama fotográfica. São Paulo: Ateliê Editorial, 1998.

KOSSOY, Boris. Fotografia e história. São Paulo: Ateliê Editorial, 2000.

NOSELLA, Paolo. A escola de Gramsci. Porto Alegre: Artes Médicas, 1992.

OLIVEIRA, Francisco. Aproximações ao Enigma: o que quer dizer desenvolvimento local? São Paulo: Instituto Polis; Programa Gestão Pública e Cidadania/EAESP/FGV, 2001.

SANTOS, Milton. Pensando o Espaço do Homem. São Paulo: Hucitec, 1997. 
SCHWARTZ, Yves. Produzir saberes entre aderência e desaderência. Revista Educação Unisinos, São Leopoldo, v. 13, n. 4, p. 264-273, set./dez. 2009.

SCHWARTZ, Yves; DURRIVE, Louis. Trabalho e Ergologia: conversas sobre a atividade humana. Niterói: UdUFF, 2007.

SCHWARTZ, Yves; DURRIVE, Louis. Glossário da Ergologia. Revista Laboreal, Porto, v. 4, n. 1, p. 23-28, jul. 2008.

SCHWARTZ, Yves; ADRIANO, Rufino; ABDERRAHMANE, Fyad. Revisitar a actividade humana para colocar as questões do desenvolvimento: projeto de uma sinergia franco-lusófona. Revista Laboreal, Porto, v. 4, n. 1, p. 10-22, jul. 2008. 
School and Local Development: meeting and clash

\begin{abstract}
It presents reflections from two case studies with student workers: the first with workers in a sugar cane plantation, in the northeast of Brazil, and one with tobaco growers, in the south. Both concern to the relationship between workers education, knowledge at work and local development. The data were produced from self-pictures, in the first study, and self- biography, in the second. Among the theoretical references, we take up Schwartz's and Charlot's thesis about knowledge production, and Francisco de Oliveira's and Milton Santos' on local development. The findings can reiterate that the school can only be of effect, when takes into account the cultural heritage of these students.
\end{abstract}

Keywords: Student Worker. Knowledge at Work. Development

\section{Escuela y Desarrollo Local: encuentros y desencuentros}

\section{Resumen}

El presente texto presenta reflexiones sobre dos estudios de caso con alumnos trabajadores: trabajadores en plantaciones de caña de azúcar en el noreste de Brazil; y otro con produtores de tabaco del sur del pais. Ambos estudios abordan la relación entre la formación de trabajadores, el conocimiento que estes producen en el trabajo y el desarrollo local. Los datos fueron producidos a partir de autofotografias en el primer estudio y autobiografías en el segundo. El estúdio se auxilia em las tesis de Schwartz y Charlot sobre saberes del trabajo; y de Francisco de Oliveira y Milton Santos sobre el desarrollo local. Los resultados afirman que la escuela sólo puede tener significado para los trabajadores si se tiene en cuenta su patrimonio cultural.

Palabras claves: Trabajador Estudiante. Conocimiento. Desarrollo

\section{Naira Lisboa Franzoi}

E-mail: nairalisboafranzoi50@gmail.com

Damiana Matos Costa França

E-mail: damianamcf@yahoo.com.br

Maria Clarice Rodrigues de Oliveira

E-mail: clarice500@gmail.com
Recebido em: 2/11/2014

Aprovado em: 14/9/2016 